\title{
Günümüzün Türkiye'sinde Mantıktaki Ana Eğilim ve Kimi Öneriler
}

\section{Main Tendency in Logic in Today's Turkey and Some Suggesstions}

\author{
Zekiye Kutlusoy $^{1}$
}

${ }^{1}$ Prof. Dr., Maltepe Üniversitesi, İnsan ve Toplum Bilimleri Fakültesi, Felsefe Bölümü, İstanbul, Türkiye

ORCID: Z.K. 0000-0002-0238-6897

\section{Sorumlu yazar/Corresponding author: Zekiye Kutlusoy, \\ Maltepe Üniversitesi, İnsan ve Toplum Bilimleri Fakültesi, Felsefe Bölümü, İstanbul, Türkiye E-mail/E-posta: \\ zekiyekutlusoy@maltepe.edu.tr}

Başvuru/Submitted: 27.11.2019 Revizyon Talebi/Revision Requested: 03.12.2019

Son Revizyon/Last Revision Received: 16.12.2019

Kabul/Accepted: 16.12 .2019

\section{Atıf/Citation:}

Kutlusoy, Zekiye. (2019). “Günümüzün Türkiye'sinde Mantıktaki Ana Eğilim ve Kimi Öneriler" Felsefe Arkivi- Archives of Philosophy, 51: 355-361.

https://doi.org/10.26650/arcp2019-5129

\section{ÖZET}

Türkiye'deki ilk Türkçe mantık kitapları 19. yüzyılın ikinci yarısında yazılır. Aristoteles'in mantık görüşlerini temel alan Farabi-ibn Sina geleneği Türkiye'deki klasik mantık alanını şekillendirirken, bu çerçevede klasik mantığın (genelde de mantığın) temel kavramları, sorun ve tartışmaları ele alınır. Özellikle 20. yüzyılın ilk yarısında yapılan çeviriler mantıkta yaşanan gelişmelerin ortaya çıkardığı öncü sembolik mantık çalışmalarını Türkiye'de tanıtırken, Reichenbach ve von Aster gibi 1933 sonrasında İstanbul Üniversitesine gelmiş olan bazı Alman felsefecilerin sembolik mantığın Türkiye'deki akademik serüveninin başlangıcına büyük katkıları olur. 21. yüzyıla gelindiğinde ise, 2014 yılında kurulan İstanbul Üniversitesi Mantık Uygulama ve Araştırma Merkezinin yanı sıra Mantık Derneği, kimi birim ve kurumlarla birlikte düzenli olarak çalıştaylar, yaz okulları, uluslararası etkinlikler vb. düzenlemeye, dahası bunları yayına dönüştürmeye de girişir. Tüm bu platformlardan, günümüzde Türkiye'de genç mantıkçıların daha çok sembolik mantık konularına yani çağdaş tartışmalara ilgi duydukları görülmektedir. Bu bağlamda genç sembolik mantıkçılara, matematik, fizik, bilgisayar bilimleri ve çeşitli mühendislik dalları gibi felsefe dışında geniş kapsamlı bir uygulama alanı bulan sembolik mantığın özellikle felsefedeki uygulamalarının, bu doğrultuda felsefeye yapabileceği katkıların, sonuç olarak da felsefe için anlam ve değerinin aydınlatılmasıyla ilgili araştırmalara yönelmeleri önerilebilir. Aslında, bu genç mantıkçıların genel olarak felsefe ve sembolik mantık arasındaki etkileşimi somutlaştıracak olan çalışmalar yapmalarının önemi son derece büyüktür. Ayrıca, onların mantık ve felsefenin yanı sıra matematik ve bilim dallarındaki gelişmeleri izleyip, bu alanlarla ilgili felsefi soruşturmalardan da haberdar olarak çalışmalarını yürütmeleri gereğine de dikkat çekilmesinde yarar vardır.

Anahtar Kelimeler: Türkiye'de klasik mantık, Türkiye'de sembolik mantık, günümüz Türkiye'sinde mantık

\section{ABSTRACT}

The first Turkish logic books in Turkey were written in the second half of the 19th century. Based on the views of Aristotle's logic, Al Farabi-Ibn Sina embodied the tradition of classical logic approach in Turkey. In this framework, studies began to investigate the basic concepts, problems and discussions of classical logic (general logic). 
Especially the first half of the 20th century translations done and developments in logic posed pioneering work of symbolic logic by introducing it to Turkey, while some German philosophers such as Reichenbach and von Aster coming to Istanbul University after 1933 made great contributions to the beginning of academic adventure of symbolic logic in Turkey. As for the 21st century, both the Istanbul University Center for Research and Practice in Logic and also the Turkish Logic Society were constituted in 2014. Since then they, together with some universities and institutions, have regularly organized workshops, summer schools, international activities etc. What is more, they have attempted to publish papers presented in these organizations too. It can be seen from all of these platforms that young logicians in today's Turkey are much more interested in issues in symbolic logic, i.e. contemporary discussions. Symbolic logic has had broad application areas in mathematics, physics, computer sciences, and various branches of engineering recently. For this reason, young symbolic logicians could be directed specifically to research on applications of logic in philosophy to illuminate the contributions, and ultimately the meaning of symbolic logic for philosophy. In fact, in order to strengthen the interaction between philosophy and symbolic logic in general, young logicians' inquiries would have a great importance. Furthermore, it would be useful to draw attention to the necessity for these logicians to carry on their studies by following developments in philosophy, logic, mathematics, and science and also by being informed about philosophical arguments related to these areas.

Keywords: Classical logic in Turkey, symbolic logic in Turkey, logic in today's Turkey

Tutarlı düşünmenin, geçerli akıl yürütmenin (koşullarının, biçimlerinin, türlerinin, ilkelerinin vb.) dil üzerinden, dil aracılığıyla, dilden yola çıkılarak soruşturulduğu mantık disiplinin kurucusu Aristoteles (İÖ 384-322), daha sonraki kimi katkılarla da geliştirilen ve 19. yüzyılın ikinci yarısına dek bütün mantık çalışmalarının konu/sorun alanını oluşturan klasik/ geleneksel mantık alanının da kurucusudur. Mantıkta modernist yaklaşımların iyice kendini gösterdiği 19. yüzyıla gelindiğinde ise Augustus De Morgan'ın ve George Boole’un 1847'de ayrı ayrı yayımladıkları mantığı formel, matematiksel bir dil çerçevesi içinde ele alan kitapları (sirasiyla Formel Mantık ve Mantığın Matematiksel Analizi), daha sonra da Gottlob Frege'nin 1879 'da yayımladığı matematiği mantıksallaştırma girişimi olarak görülebilecek olan kitabı (Kavram Yazıları) ile sembolik/modern mantığın formel bir disiplin olarak ortaya çıktı̆̆ı görülür.

Tarihsel açıdan değerlendirildiğinde, günümüzde Türkiye'deki bütün mantık çalışmalarının öncüsü olan ilk Türkçe çalışmaların (hem Aristoteles kökenli klasik hem de özellikle Frege'nin yolunu açmış olduğu sembolik mantık çalışmalarının) 19. yüzyılın ikinci yarısında Tanzimat'ın etkisiyle başladığı söylenebilir. Daha önceleri mantık dersleri geleneksel şekilde Arapça öğretilmekte ve mantık kitapları Arapça yazılmakta iken, ilk Türkçe mantıksal çalışma -Osmanlı İmparatorluğundaki modernleşme hareketinin doğurduğu reformlar ve yeniden düzenlemelerden ötürü Osmanlı tarihinin ilk demokratik anayasal süreci olarak, 3 Kasım 1839'da ilan edilen Tanzimat Fermanı ile 23 Aralık 1876'da ilan edilen I. Meşrutiyet arasındaki- Tanzimat Döneminde ortaya çıkar. Bu ilk Türkçe mantık kitabı 1876 yılında yayımlanan, Ahmet Cevdet Paşa’nın (1822-1895) geleneğe uygun olarak yazdığı ve ağırlıklı olarak bilimsel yöntemi ele aldığı klasik mantık kitabıdır (Miyar-ı Sedad). Bir hukukçu, tarihçi, dilbilimci, şair, edebiyatçı, bilim ve devlet adamı olan Ahmet Cevdet Paşa, ilk Türk kadın roman yazarı Fatma Aliye’nin yanı sıra yazmış olduğu mantık kitaplarıyla tanınan Ali Sedat'ın da babasıdır. 
Temelini Aristoteles'in mantık görüşlerini içeren ve sonradan "Organon” olarak adlandırılan altı kitapla (Kategoriler, Yorum Üzerine, Birinci Çözümseller, İkinci Çözümseller, Topikler ve Sofistik Çürütmeler), bunlara İS 3. yüzyılda eklenen Aristoteles'in Retorik ve Poetika kitaplarının yanı sıra Porphyrios'un kitabı Ísagoge’ nin oluşturduğu mantıksal çerçeve, 9.-12. yüzyıllar arasında İslam Felsefesini büyük ölçüde etkileyerek Ortaçağın büyük Türk düşünürleri Farabi (870-950) ve İbn Sina’nın (980-1037) yaklaşımları doğrultusunda gelişen mantık geleneğinin oluşumunun yolunu açmış, daha sonra da bu gelenek Türkiye'deki klasik mantık alanını şekillendirmiştir. 20. yüzyılda Necati Öner’in ardından, Şafak Ural, Cemal Yıldırım, Doğan Özlem, A. Kadir Çüçen ve İbrahim Emiroğlu gibi mantıkçı yazarlar eserleriyle bu mantık alanının tanıtılmasına büyük katkıda bulunurlar.

Sembolik mantık ise, ilk olarak, yine 19. yüzyılın ikinci yarısında Ahmet Cevdet Paşa'nın oğlu Ali Sedat (1857-1900) tarafindan yazılan ve 1885 'te yayımlanan kitabın yanı sıra İsmail Hakkı İzmirli'nin kitaplarında tanıtılır. Türkiye'deki felsefeciler ve mantıkçılar, Frege'yi izleyen Bertrand Russell ve Alfred North Whitehead'in birlikte yazmış olduğu, 3 cilt halinde 1911 ve 1913 yılları arasında yayımlanan Principia Mathematica'dan ise ilk kez 1920'lerde Salih Zeki'nin Henri Poincaréden yapmış olduğu bir çeviri sayesinde haberdar olurlar. Kerim Erim, Nusret Hızır, Macit Gökberk ve Halil Vehbi Eralp gibi akademisyenler birçok sembolik mantık yazısını o yıllarda Türkçeye çevirirler. Öte yandan, ilk matematiksel mantık dersleri akademik çatı altında 1933-1938 yılları arasında Hans Reichenbach tarafından İstanbul Üniversitesi Edebiyat Fakültesi Felsefe Bölümünde verilirken, bu “(yep)yeni” mantığa ilişkin derslerde Macit Gökberk ve Nusret Hızır Reichenbach’ın sınıftaki sözlerini Almancadan Türkçeye, Halil Vehbi Eralp de Fransızcadan Türkçeye çevirirler. Salih Zeki'nin 1916'da yayımlanan cebirsel mantık kitabından ve Kerim Erim'in çalışmalarından sonra, sembolik mantıktaki ilk makaleleri Nusret Hızır yazar. Daha sonraları Ankara Üniversitesinde sembolik mantık dersleri vermeyi sürdüren Hızır, 19451947 yılları arasındaki yayınlarında çok-değerli mantık sistemlerini de ele alır. Nazilerden kaçarak İstanbul Üniversitesine gelmiş olan kimi Alman felsefecilerin, sembolik mantığın Türkiye'deki akademik serüveninin başlangıcında büyük bir etkisinin olduğu ise açıktır. Reichenbach'ın hemen ardından gelen Ernst von Aster, 1935-1948 arasında bu üniversitede verdiği felsefe tarihi derslerinde mantık konularını bilgi kuramı kapsamında ele almış, Freytag Loringhoff ise mantık derslerinde öğrencileri felsefi mantık sistemleri gibi mantıktaki yeni gelişmelerle tanıştırırken onlar üzerinde tartışmalar yürütmüştür. 1961'den 1966'da ODTÜ'de çalışmaya başlayana dek yine bu üniversitede önce konferansçı sonra uzman olarak sembolik mantık dersleri veren Teo Grünberg ile Reichenbach'ın 1938'deki gidişinden yani yirmi üç yıllık bir aradan sonra bu dersler tekrar verilmeye başlanmıştır. Türkiye'deki sembolik mantığın gerçek öncüsü, -1960 'ların başından beri önermeler mantığı, modern mantığın uygulamaları, epistemik mantık (bilgi mantığı) ve sorular mantığının yanı sıra diğer özel mantık sistemleri, anlamın mantıksal kuramı, kümeler kuramı, sentaktik kategoriler, mantıksal değişmezler, değişkensiz niceleme ya da yüklem işlevleri (yüklem funktorları) mantığı, sayısal niceleyiciler, mantık terimleri ya da mantığın kavramsal çerçevesi ve mantık felsefesi sorunları gibi konulara ilişkin çalışmalarını sürdürmekte olan- Grünberg’tir. Hilmi Ziya Ülken ve Dursun M. Çüçen'in ardından, Grünberg'in yanı sıra Doğan Özlem, 
Ahmet İnam, Şafak Ural, Ali Karatay gibi düşünürler ve H. Bülent Gözkân, Ayhan Çitil, İskender Taşdelen, M. Nazlı İnönü, Aziz F. Zambak, A. Kadir Çüçen, Yücel Yüksel, Özgüç Güven, Burhan Türkşen, Zekai Şen, Vedat Kamer ve Zekiye Kutlusoy gibi daha sonraki kuşaklardan mantıkçılar sembolik mantığın konuları, sorunları ve yöntemleri üzerine çalışmalarını sürdürürler.

Şimdi, ülkemizde günümüzün mantık alanındaki genç araştırmacılarına ve onların eğilimlerine gelinecek olursa, bunların kabaca da olsa netleştirilmesi için yardımcı olacak olan son yıllardaki önemli bir gelişme, 2014 yılında Prof. Dr. Şafak Ural'ın önderliğinde İstanbul Üniversitesi Mantık Uygulama ve Araştırma Merkezinin yanı sıra Mantık Derneğinin de kurulmasıdır. Bu merkezin önemli bir amacı uluslararası etkinlikler gerçekleştirebilmek için ilgili kurumlar ile yakın ilişkiler kurmak iken, dernek de hem lise hem de özellikle -matematik, bilgisayar bilimleri ve dilbilim gibi bölümlerde okuyan - üniversite öğrencilerinin dikkatlerini mantığa çekmeyi, genel olarak da insanlarda mantığın önemine ilişkin olarak bir farkındalık ve duyarlılık geliştirmeyi hedeflemekte, mantık, matematiksel mantık, yapay zekâ ve dilbilim gibi dalların disiplinlerarası çalışmalarına bir alan açmak çabasındadır.

Belirtilen amaçlar doğrultusunda söz konusu merkez ve dernek, İstanbul Üniversitesi Edebiyat Fakültesi Felsefe Bölümü Mantık Anabilim Dalının yanı sıra her yıl ev sahipliğini üstlenen ayrı bir üniversitenin ilgili birimleri ile birlikte - Türkiye'deki mantıkçlları ve bu alandaki araştırmacıları aynı çatı altında bir araya getirmek amacıyla- bir mantık çalıştayı düzenlemekte (aslında bu çalıştaylar 2012 yılında yapılmaya başlanmıştır), 2016 yılından beri de o yılki çalıştayda sunulmuş olan bildirileri yayımlamaktadır (https://calistay.mantik.org.tr/; https://mantik.org.tr/). Bu çalıştaylar şunlardır: I. Mantık Çalıştayı, 25-26 Haziran 2012, İstanbul; II. Mantık Çalıştayı, 3-4 Mayıs 2013, Eskişehir; III. Mantık Çalıştayı, 28 Şubat-1 Mart 2014, Amasya; Uluslararası IV. Mantık Çalıştayı, 19-20 Haziran 2014, Bulgaristan; V. Mantık Çalıştayı, 15-16 Mayıs 2015, Bursa; VI. Mantık Çalıştayı, 26-27 Mayıs 2016, Artvin; VII. Mantık Çalıştayı, 29-30 Haziran 2017, Samsun; VIII. Mantık Çalıştayı, 9-11 Mayıs 2018, Zonguldak; Uluslararası IX. Mantık Çalıştayı, 18-19 Nisan 2019, Mardin. Dahası sözü edilen merkez, dernek ve anabilim dalı, 2015 yılından başlayarak beş kez de Boğaziçi Üniversitesi Feza Gürsey Fizik ve Matematik Uygulama ve Araştırma Merkezinde temel düzey ve ileri düzey olmak üzere iki düzey halinde düzenledikleri mantık yaz okulları kapsamında çeşitli mantık dersleri vermişler, ayrıca 2015 Haziranında İstanbul'da UNILOG 2015: 5. Evrensel Mantık Dünya Kongresi ve Okuluna da ev sahipliği yapıp bu etkinliklere ilişkin bir derleme de yayımlamışlar (http://www.uni-log.org/hunilog2015. pdf), tüm bunlardan başka da 26-27 Ekim 2019 tarihlerinde İstanbul Üniversitesi Bilgisayar Bilimleri Uygulama ve Araştırma Merkezi ve Enformatik Bölümünün yanı sıra ODTÜ-TSK MODSİMMER Berimsel Ontoloji Laboratuvarı ve Felsefe Bölümü ile birlikte Yapay Zekâ ve Formel Ontoloji Atölyesi düzenlemişlerdir.

Şimdi, Mantık Derneğinin web sitesinden kolaylıkla erişilebilen söz konusu tüm bu etkinlikler çerçevesinde sunulan bildiriler, verilen dersler, yürütülen tartışmalar, yapılan yayın ve atölye çalışmalarından, günümüzde genç mantıkçı akademisyen ve araştırmacıların ağırlıklı olarak sembolik/modern mantık kapsamındaki konulara veya bu alanla ilişkili olabilecek çağdaş mantık 
sorunlarına odaklandıkları görülmektedir. Bu türden içeriklerle ilgili olan genç akademisyenlerin en azından bir kısmının ise yüksek lisans/doktora tez çalışmalarında bu konulara yönelmiş ya da yönelecek olmaları da doğaldır. Ülkemizdeki felsefe veya felsefe grubu öğretmenliği alanlarının lisans düzeyindeki eğitim-öğretim programları kapsamında genellikle 3-ilkeli, 2-değerli klasik mantığın devamı niteliğindeki, doğruluk-fonksiyonu mantığını da içeren niceleme/yüklemler mantığının oluşturmuş olduğu temel sembolik mantık düzeyinde kalınıyor olmasına karşın genç araştırmacıların bu düzeyi oldukça aşmış bulunan mantıktaki güncel tartışmalardan ve yeni gelişmelerden haberdar olmaları, kimilerinin belli bir tema doğrultusunda kararlılıkla ilerleyerek kendilerini geliştirmeye çalışmaları da bayağı sevindiricidir. Ancak, yine de ister salt mantık alanında kuramsal olarak çalışıyor olsunlar, ister mantığın uygulamalarıyla ilgili olarak araştırmalar yapıyor olsunlar yollarının başındaki genç sembolik mantıkçılara aşağıda yer alan kimi önerilerde bulunmak olanaklı görünüyor.

Geçen yüzyıldan itibaren matematik, fizik, bilgisayar bilimleri ve çeşitli mühendislik dalları gibi farklı araştırma çevrelerinde oldukça geniş kapsamlı bir uygulama alanı bulan sembolik mantığın aslında felsefeden kopmuş ya da kopmakta olduğu düşünülebilse bile, felsefe açısından öncelikle yapılması gereken bu mantık alanının felsefe için işlevsel öneminin netleştirilmesidir. Bunun gerçekleştirilmesi ise pekâlâ genç sembolik mantıkçılardan beklenebilir. Bu amaç doğrultusunda onlar günlük/doğal dil önermelerini yalnızca dilbilgisel yapıları (yani gramer) açısından değil mantıksal formları bakımından da çözümleyip formel bir dil içinde yeniden formüle eden sembolik mantığın, felsefenin klasik mantık, dil felsefesi, bilim felsefesi, matematik felsefesi, bilgi felsefesi ve zihin felsefesi gibi alanlarına ilişkin uygulamaları aracılığıyla bu alanlara, genel olarak da felsefeye yaptığı/yapabileceği katkıları aydınlığa kavuşturabilirler. (Sembolik mantığın bu türden uygulamalarıyla ilgili örneğin klasik mantığın basit kategorik önermeleri olan tümel/tikel genellemelerin aslında bileşik yapıdaki önermeler olduklarının temellendirilmesi ya da çoklu-yüklemlerin, özelliklerin gösterildiği tekli-yüklemlere indirgenmeyip, bağıntıların ayrıca gösterilebilmesindeki rolünün belirginleştirilmesi, kümeler kuramı çerçevesindeki tartışmaların veya metodolojik bir sorgulama bağlamında bilimin mantığına ilişkin irdelemelerin sürdürülmesi, mantığın gerçeklik alanına yani empirik olana ilişkin bilgi edinmedeki işlevinin/ görevinin yöntemsel olarak netleştirilmesi gibi bazı somut örnekler ve açıklamalar için bkz. Kutlusoy, 2003: 140-143, 148/27. not; Rossi, 2001: 5-12; Kutlusoy, 2016: 248, 249-250.)

Sembolik mantığın felsefeye yönelik olarak yaptığı katkıların yanı sıra felsefi irdelemelerin yani felsefenin de kavramsal düzeyde güçlüklerinin aşılmasında sembolik mantığa destek vermekte olduğu açıktır (örneğin özel mantık sistemleri kurulurken onlara özgü yeni mantıksal değişmezler olan işlemciler/yöneticiler, ilgili felsefe alanında yürütülen kavramsal çözümlemelerle belirginleştirilmektedirler). Bundan ötürü genç sembolik mantıkçıların, günümüzde ele aldıkları çağdaş sorun ya da konuların felsefi soruşturma çerçevesinin neresine, ne şekilde oturduğunun ya da nasıl eklemlendiğinin (veya nasıl eklemlenebileceğinin) farkında olarak, felsefe ve sembolik mantık arasındaki bağ(lantıy)ı net bir biçimde kurabilmeleri ve de böyle bir ilişkilendirmenin bilinçli olarak hesabını verebilmeleri gerekmektedir (bu bakış açısından, örneğin yapay zekâ algoritmaları ile ilgili çalışmalar yürüten bir mantıkçının, çalışmalarının bilişsel sinirbilim, 
bilişsel psikoloji, bilişsel dilbilim ve yapay zekâ araştırmaları gibi disiplinlerin oluşturduğu bilişsel bilimle sıkı etkileşim halindeki çağdaş zihin felsefesiyle olan ilişkisinin bilincinde olmasının beklenmesi hiç de yadırgatıcı olmamalıdır). Onun için bu genç mantıkçıların mantığın tarihsel serüveninden ve gelişim sürecinden haberdar olup, öncelikle de temel düzeydeki tartışmaları doğru değerlendirebilecek donanıma sahip olmaları gerçekten önemlidir.

Sembolik mantığın 20. yüzyılın ilk yarısında hem kendi içinde hem de dışında yaşanan gelişmeler, onun hızla gelişmekte olan konu/sorun alanında kimi değişim ve dönüşümlere yol açar. Örneğin fazla kaplamsal olduğu için günlük dili tam ve yeterli bir biçimde karşılayamadığı düşünülerek eleştirilen sembolik mantığa, daha açık bir deyişle mantığın formel diline içlemsel/ anlamsal bir nitelik kazandırmak için mantık felsefesi kapsamında yürütülen tartışmalar, dilin semantik boyutunu öne çıkararak kipler mantığı, ödev mantığı, zaman mantığı ve bilgi mantığı gibi özel mantık sistemlerinin (felsefi mantıkların) yanı sıra "normalden sapmış mantıklar" olarak nitelenen yani klasik olmayan 3-değerli mantık, olasılık mantığı, sezgici mantık ve puslu/ bulanık mantık gibi çok-değerli mantıkların geliştirilmesine de neden olur (Kutlusoy, 2016: 245-246; Rossi, 2001: 73-74). Öte yandan, bu semantik temelli arayışların sonucunda kurulan farklı farklı mantıkların ortaya çıkardığı "mantıklar çoğulluğu”, mantığın tekliğinin/birliğinin parçalanmışlı̆̆ını sergilerken mantığın a prioriliğini ve analitikliğini de tartışmaya açar (Rossi, 2001: 76).

İşte bu ve benzeri tartışmalardan yola çıkılarak, temel mantığın ilkelerinin tümünü birden kabul etmeyen çok-değerli mantıkları olmasa da ilgili felsefi alana özgü, özel türden bir önerme eklemi konumundaki yeni mantıksal değişmezlerin, aksiyomatik bir yapı içinde tanımlanarak temel sembolik mantığa eklenmesiyle oluşturulan özel/felsefi mantık sistemlerini ya da en azından onların bir kısmını kuşatacak bir mantık çerçevesinin geliştirilip geliştirilemeyeceği, birbirine rakip olan mantıksal yaklaşımlardan hangisinin nasıl seçilebileceği, bu bağlamda ontolojik önkabulleri açığa çıkarılarak aydınlatılan farklı içlemsel mantıkların birbirleriyle nasıl karşılaştırılabileceği gibi mantık felsefesi sorunları da genç mantıkçılar için oldukça verimli tartışma bağlamları üretebilir.

Diğer taraftan, matematik ve bilim gibi mantığın/felsefenin dışındaki alanlarda yaşanan gelişmelerle kendini gösteren gereksinimler de mantıktan yeni yaklaşımların talep edilmesinin yolunu açar. Örneğin aritmetiğin aksiyomatikleştirilmesinde kullanılan aksiyomlardan biri olarak sayılar arasındaki ardışıklık (ya da ardıllık) bağıntısını dile getiren ardışıklık aksiyomu için bağıntılara gereksinim duyulması, klasik mantıkta yapılanın tersine sembolik mantıkta bağıntıların ayrıca ele alınarak irdelenmesini gerektirir (Kutlusoy, 2003: 141; Rossi, 2001: 1011). Bilimde ise 18. yüzyıldan beri etkin bir biçimde süregelmekte olan determinist nedensellik kavrayışı, atom-altı gerçeklik alanındaki parçacıkların devinimlerine ilişkin olarak geliştirilen kuantum kuramının etkisiyle olasılıksal (ya da olasılıkçı) bir nedensellik yaklaşımına evrilirken, böyle bir kuramsal çerçeve de alışılmış klasik düşünme ve söylem biçimlerinden başka yeni bir mantık anlayışının (ki bu, çok-değerli bir mantık anlayışıdır) geliştirilmesini kaçınılmaz kılar (Kutlusoy, 2016: 257-258; Yıldırım, 1998: 119-131; Yıldırım, 2008: 175-191). 
Bu gibi konularda yani matematik ve bilim alanlarıla bağlantılı olarak çalışmak isteyen genç mantıkçıların ise belli bir düzeyde de olsa matematik ve fizik eğitimi almalarının, dahası matematik felsefesi, bilim felsefesi ve çağdaş dil felsefesi alanlarındaki sorun ve sorgulamaları tanımalarının, onları araştırmalarında ne denli şanslı kılacağı açıktır (bu türden bölümlerden mezun olup felsefeye ve mantığa merak duyan gençler de ayrıca sembolik mantıkta lisansüstü çalışmalar yapmaya özendirilip yüreklendirilebilirler).

Sonuç olarak, genç mantıkçılar için, ilgili olunan doğrultuda, hem mantık tarihindeki güçlüklerin ve onların giderilmesine yönelik çözüm önerileri kapsamındaki tartışmaların yanı sıra analitik felsefe geleneğindeki soruşturmalara da tanıdık olmanın, hem de felsefe, matematik ve bilimdeki gelişmeleri yakından izleyerek tanımanın getireceği yarar büyüktür. Zaman içinde ortaya çıkabilecek olan gereksinimlerin karşılanmasını ve sorunların çözülmesini hedeflemeleri durumunda, onlar için, örneğin yetkin bir formel sentaks temeline sahip bir mantık sistemi ve onun önermelerini yorumlamaya yarayacak bir formel semantik kurmak ya da zaten kullanılmakta olan eldeki mantıksal yapıları geliştirmek, ancak bu şekilde olanaklı olabilecektir.

Finansal Destek: Yazar bu çalışma için finansal destek almamıştır.

\section{Kaynaklar}

Kutlusoy, Zekiye (2003) Temel Sembolik Mantık, Ankara: Art Basın Yayın.

Kutlusoy, Zekiye (2016) "Mantık Felsefesinde Semantik Tartışmalar”, V. Mantık Çalı̧stayı Bildiri Kitabı, ed. A. Kadir Çüçen, Bursa: Sentez Yayıncılık, 245-266.

Rossi, Jean-Gérard (2001) Analitik Felsefe, çev. Atakan Altınörs, İstanbul: Paradigma Yayınları.

Yıldırım, Cemal (1998) Bilim Felsefesi, İstanbul: Remzi Kitabevi, 6. Basım.

Yıldırım, Cemal (2008) Bilimsel Düşünme Yöntemi, Ankara: İmge Kitabevi, 2. Basım. 
